\title{
INFLUENCE OF INTRACAVITY POWER ON FREQUENCY CHARACTERISTICS OF IODINE-STABILIZED He-Ne LASER
}

\begin{abstract}
Summary
Following a shift in the industry to solid-state lasers during the past decade, resonator tubes which can be used in iodine-stabilized helium-neon (He-Ne) lasers are being discontinued by most manufacturers. After installing a replacement tube, it was discovered that its intracavity power was not equal to that of the original tube. The influence of this change on the uncertainty of frequency was determined over the course of several months. Mirrors in the optical cavity were adjusted for optimal intracavity power using short heterodyne beat frequency measurements with a reference laser. Data for stability and absolute value of the reference frequency were well-known and provided in advance by calibration with the comb method. The sensitivity coefficient of the output beam power was estimated from beat frequency deviations measured at several values of power inside the range of the stabile operation of the laser. Finally, a long-term measurement of beat frequency provided data about the stability and frequency offset.
\end{abstract}

Key words: $\quad$ laser, frequency stability, traceability, optical interferometry

\section{Introduction}

Traceability of length measurements to the SI unit metre is realized by means of interferometry, and primary interferometers are used at the highest accuracy levels to perform calibration of national standards. These devices are expensive, given the fact that they are manufactured on order and used almost exclusively by national measurement institutes. Reliable primary frequency standard is of highest national metrological interest in the sense of assuring high-level calibrations and industrial measurements of length. At the time of adoption of the present definition of metre (as the length of the path travelled by light in vacuum during a time interval of 1/299 792458 of a second) the International Committee for Weights and Measures (CIPM) drew up recommendations for the practical realization of the definition, called Mise en Pratique (MEP). CIPM currently recommends the iodine-stabilized $\mathrm{He}-\mathrm{Ne}$ laser as a frequency standard with its f-component of $473612353604 \mathrm{kHz}$ and standard deviation (StDev) less than $10 \mathrm{kHz}$. To ensure the stated frequency stability appropriate optical and electronic control systems have to be provided and the operational parameters have to be adjusted to the recommended values [1]. 
Such an iodine-stabilized He-Ne laser, named MIRS1, was used at the Laboratory for Production Measurements at the Faculty of Mechanical Engineering, University of Maribor (a nationally designated metrology institute of EURAMET), for the calibration of He-Ne lasers that are used for laboratory and industrial interferometry [2]. Inside the laboratory traceability chain, a secondary He-Ne laser interferometer, calibrated by MIRS1, is for instance used for calibrating the precise line scales, which are the most common measurement standards for assuring industrial traceability of optical measuring equipment, such as microscopes, profile projectors and digital vision systems [3].

Similarly, an iodine-stabilized He-Ne laser, named LPMD1, was used at the National Laboratory for Length at the Faculty of Mechanical Engineering and Naval Architecture, University of Zagreb, for high-level calibrations, such as direct calibration of gauge blocks [4]. Both lasers joined the CCL-K11 key comparison, the inter-comparison of primary standard lasers supported by CIPM [5]. According to the results, both were included into the CIPM MRA KCDB database and the national accreditation list. For maintaining the highlevel calibration and measurement capability, the laboratories are steadily involved in international and regional inter-comparison projects [6 -8].

Periodical tests of the calibration capability are needed in order to maintain confidence in performance of the described lasers. The highly precise way of testing is comb measurement at a pilot laboratory, as recommended by CIPM at least once in ten years. For frequent tests inside the laboratory, a much less precise, yet a simple and effective method is a short measurement using a highly stable secondary laser at successively locked peaks [9]. Furthermore, a way that is more accurate is the inter-laboratory comparison by heterodyne matrix measurements carried out with a similar primary laser, which yields a mutual uncertainty of both lasers. Such measurements were performed for a new resonant tube (Melles Griot 05-LHB-294) installed into the LPMD1 laser and adjusted by using the MIRS1 laser as a reference. Its intracavity power was simulated to find the optimal value within the MEP recommendations. Better results may be obtained either by accurately determining the values of the main parameters influencing the laser frequency or by adjusting the intracavity power close to the value recommended by MEP and avoiding large corrections.

\section{Experimental set-up}

The resonator in the laser is made of a tube located between two mirrors, which are both attached to piezoelectric transducer actuators, so the cavity length can be precisely adjusted by a voltage supply. The operational principle is to keep the cavity length resonant to one of seven hyper-fine transitions of molecular iodine electronically controlled by the third harmonic technique [9]. The user can lock the chosen frequency among seven peaks, named quadruplet $\mathrm{d}, \mathrm{e}, \mathrm{f}, \mathrm{g}$ and triplet $\mathrm{h}, \mathrm{i}, \mathrm{j}$.

Upon starting the laser, the internal temperature of the resonator is stabilized within a few hours, and in normal laboratory conditions, the laser is able to keep a frequency locked for days. The control electronics of the laser enables the adjustment of the control parameters. Iodine cold finger temperature (CFT), cell-wall radiation temperature (RT), modulation width (MW) and intracavity beam power $(P)$ as the most influencing parameters are adjusted to the values recommended by CIPM [1].

A new resonant tube was installed into the LPMD1 laser at the National Laboratory for Length and the tube power was adjusted by using the MIRS1 laser from the Laboratory for Production Measurements. For this purpose, the beat frequency measurements were performed with a set-up presented in Fig. 1. Along the optical path, i.e. between the splitter and the 
detector, the reference beam from the MIRS1 laser and the measured beam from the LPMD1 laser were aligned, so the co-propagated beams produced the pulsation with beat frequency $\Delta v=\left|v_{1}-v_{2}\right|$. Two mirrors and the beam splitter were used to align the beams into one axis, and then the half-wave plate and the linear polarizer were rotated to align the linear polarization planes of the beams into the vertical plane. The beat frequency was measured by an AVM-02 photodetector (Laser Metrology from Poland), a combination of a highly sensitive photodiode and a frequency counter, especially designed to be used in laser comparisons. Connected to a $\mathrm{PC}$, an adequate program "Freqmeter" allows the Allan variance calculation at averaging periods from $100 \mu \mathrm{s}$ to $1000 \mathrm{~s}$ to be performed. For preliminary observations, a Hameg HMS 1000 spectrum analyser was used. When the beams are precisely aligned, the signal on the spectrum analyser will be symmetrical and its centre equal to the value shown in the PC software (Fig. 2.c). The harmonics peaks, seen on the screen (Fig. 2.d, e; for instance, the second peak as the double value of the basic peak), are much weaker, so the counted value in Freqmeter (Fig.2.c) can be associated to the basic frequency peak (Fig. 2.f).

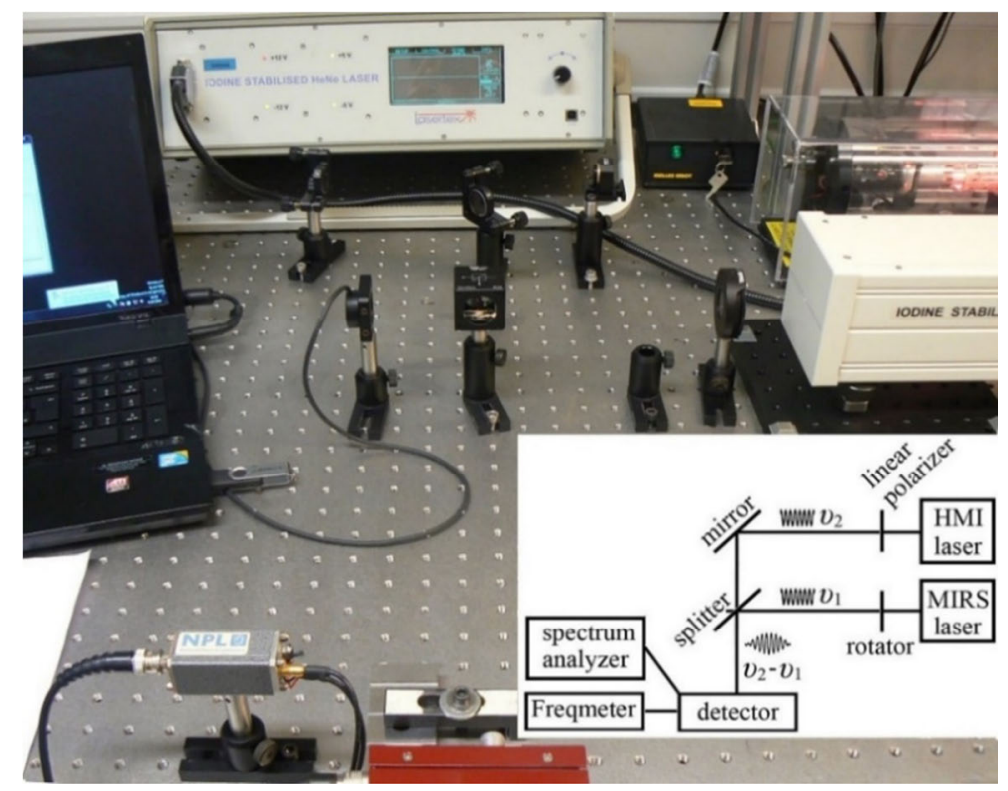

Fig. 1 Assembly for beat frequency measurement
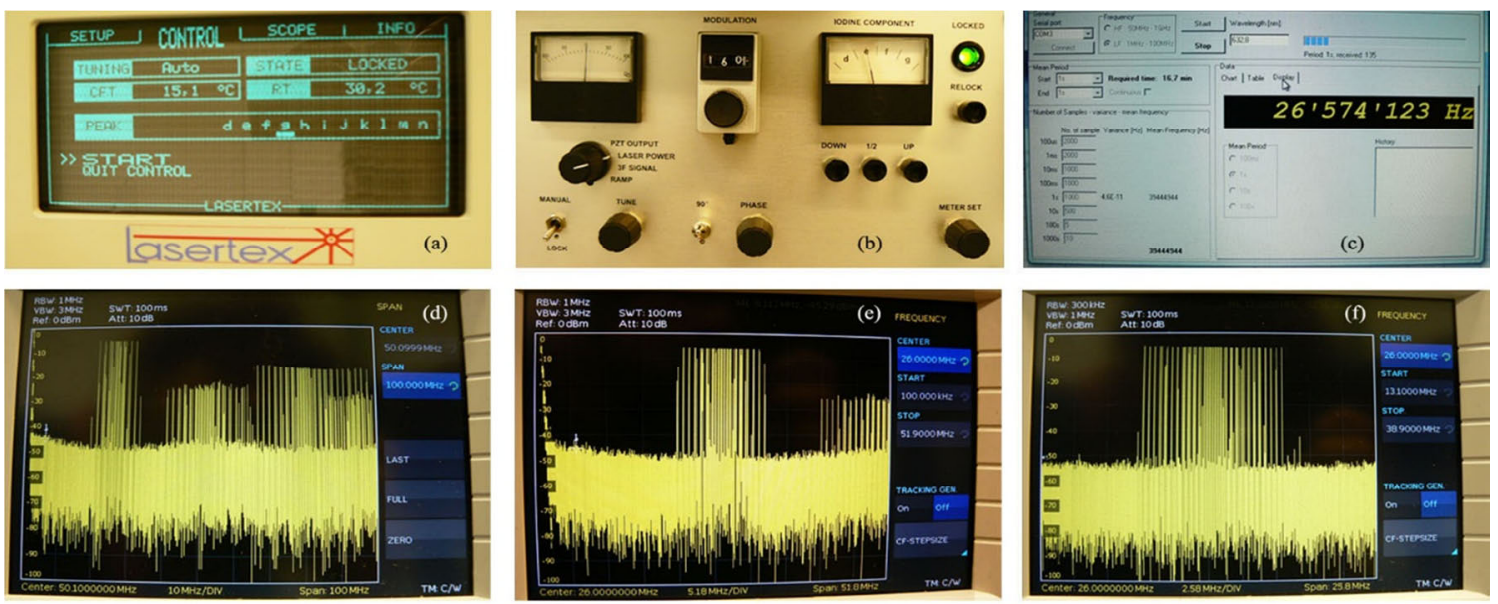

Fig. 2 Display: (a) Control device for MIRS1 with locked g peak;

(b) Control device for LPMD1 with locked e peak; (c) Beat frequency monitored by PC software;

(d) Beat frequency on spectrum analyzer at $\mathrm{Span}=100 \mathrm{MHz}$ and Centre $=50 \mathrm{MHz}$,

(e) at Span $=52 \mathrm{MHz}$ and Centre $=26 \mathrm{MHz}$, (f) at $\mathrm{Span}=26 \mathrm{MHz}$ and Centre $=26 \mathrm{MHz}$ 


\section{Results and discussion}

Both lasers were running continuously during measurements and the power was simulated for adjusting the LPMD1's resonant tube under the same conditions and operational parameters as normally used. The parameters and their coefficients were known for both lasers, except for the power coefficient of the new tube. The power was adjusted within the recommendation $(100 \pm 50) \mu \mathrm{W}$. The absolute frequency of MIRS1 was checked by comb measurements before and after the presented inter-comparison, being $\mathrm{f}=473612353604 \mathrm{kHz}$ with stability given in Table 3.b. The frequency stability was observed at different sampling periods, with the relative Allan standard deviation (ASD), normalised with absolute frequency f. For this purpose, the beat frequency was measured at the sampling time of $1 \mathrm{~s}$, then recalculated for $10 \mathrm{~s}$ taking the average beat frequency for packages of ten preliminary values, and so on for longer sampling periods, depending on the length of the whole measurement as at least four packages are needed for the calculation of ASD.

Table 1 Matrix peak-peak measurements (1000 x $1 \mathrm{~s}$ sampling); average power of MIRS1 laser $P_{1}=103.5 \mu \mathrm{W}$, and of LPMD1 laser $P_{2}=125 \mu \mathrm{W}$; peak locked in MIRS1 is indexed with 1 and in LPMD1 with 2.

\begin{tabular}{|c|c|c|c|c|c|c|}
\hline \multirow[t]{2}{*}{ Pair } & \multicolumn{2}{|c|}{ Peak-peak difference (MHz) } & \multirow{2}{*}{$\begin{array}{c}\text { Deviation }(\mathrm{kHz}) \\
\text { (measured }- \text { theoretical) }\end{array}$} & \multicolumn{3}{|c|}{$\operatorname{ASD}\left(\cdot 10^{-12}\right)$} \\
\hline & theoretical & measured & & $\tau=1 \mathrm{~s}$ & $\tau=10 \mathrm{~s}$ & $\tau=100 \mathrm{~s}$ \\
\hline $\mathrm{d}_{1}-\mathrm{e}_{2}$ & 12.861 & 12.8400 & -21.0 & 28.2 & 6.8 & 2.0 \\
\hline $\mathrm{d}_{1}-\mathrm{f}_{2}$ & 26.224 & 26.2070 & -16.9 & 23.2 & 6.4 & 1.9 \\
\hline $\mathrm{d}_{1}-\mathrm{g}_{2}$ & 39.422 & 39.4054 & -16.6 & 30.9 & 7.1 & 1.4 \\
\hline $\mathrm{e}_{1}-\mathrm{g}_{2}$ & 26.561 & 26.5440 & -17.0 & 25.0 & 5.9 & 1.6 \\
\hline$f_{1}-g_{2}$ & 13.198 & 13.1819 & -16.1 & 29.4 & 6.7 & 2.0 \\
\hline$f_{1}-e_{2}$ & 13.363 & 13.3760 & +13.0 & 28.9 & 10.1 & 2.7 \\
\hline $\mathrm{f}_{1}-\mathrm{d}_{2}$ & 26.224 & 26.2369 & +12.9 & 27.0 & 7.0 & 2.2 \\
\hline $\mathrm{g}_{1}-\mathrm{d}_{2}$ & 39.422 & 39.4359 & +13.9 & 24.8 & 6.3 & 1.8 \\
\hline$e_{1}-d_{2}$ & 12.861 & 12.8805 & +19.5 & 23.2 & 5.5 & 1.9 \\
\hline$e_{1}-f_{2}$ & 13.363 & 13.3426 & -20.4 & 27.2 & 6.3 & 2.1 \\
\hline $\mathrm{g}_{1}-\mathrm{f}_{2}$ & 13.198 & 13.2186 & +20.6 & 25.0 & 6.5 & 1.4 \\
\hline $\mathrm{g}_{1}-\mathrm{e}_{2}$ & 26.561 & 26.5778 & +16.8 & 25.7 & 5.8 & 1.7 \\
\hline \multicolumn{3}{|c|}{ Average } & 17.3 & 26.5 & 6.7 & 1.9 \\
\hline
\end{tabular}

Table 2 Measurement $\mathrm{g}_{1} \mathrm{e}_{2}(1600 \times 10 \mathrm{~s})$

\begin{tabular}{|c|c|c|}
\hline $\begin{array}{c}\text { Time sequences } \\
(\text { sample number })\end{array}$ & $\begin{array}{c}\text { Deviation } \\
(\mathrm{kHz})\end{array}$ & $\begin{array}{c}\text { StDev } \\
(\mathrm{kHz})\end{array}$ \\
\hline $0-100$ & 14.9 & 3.2 \\
\hline $100-200$ & 18.7 & 3.3 \\
\hline $200-300$ & 21.5 & 2.9 \\
\hline $300-400$ & 22.1 & 3.2 \\
\hline $400-500$ & 20.8 & 2.6 \\
\hline $500-600$ & 18.0 & 3.0 \\
\hline $600-700$ & 18.4 & 3.4 \\
\hline $700-800$ & 18.3 & 4.3 \\
\hline $800-900$ & 15.9 & 4.4 \\
\hline $900-1000$ & 11.7 & 4.1 \\
\hline $1000-1100$ & 12.9 & 2.9 \\
\hline $1100-1200$ & 14.8 & 2.5 \\
\hline $1200-1300$ & 17.6 & 3.0 \\
\hline $1300-1400$ & 17.5 & 2.6 \\
\hline $1400-1500$ & 17.3 & 3.1 \\
\hline $1500-1600$ & 16.9 & 3.1 \\
\hline \hline Average & 17.3 & 3.2 \\
\hline
\end{tabular}

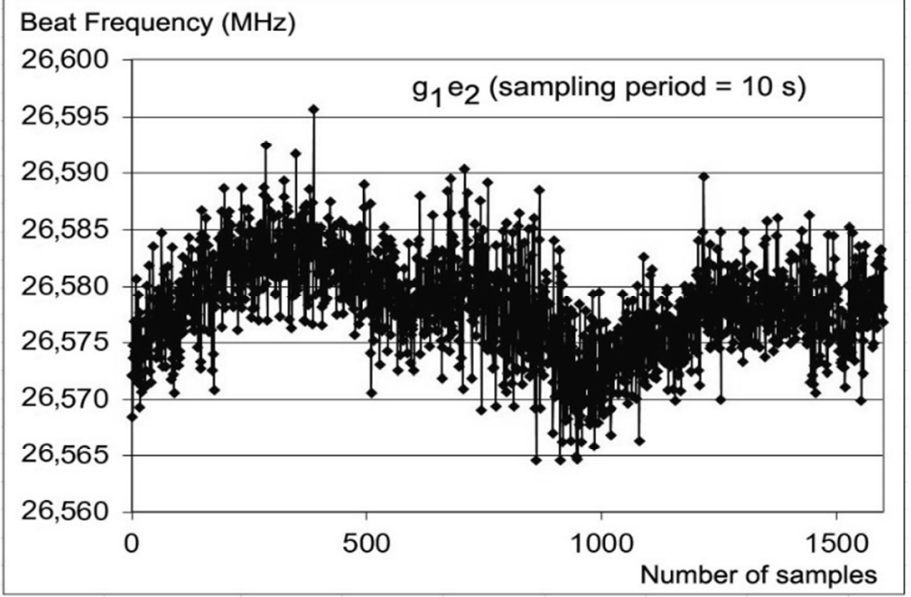

Fig. 3 Long-term measurement: 1600 x $10 \mathrm{~s}$ of sampling period, at average power of MIRS laser $P_{1}=103.5 \mu \mathrm{W}$, and of LPMD1 laser $P_{2}=125 \mu \mathrm{W}$; MIRS1 with locked peak $\mathrm{g}_{1}$ and LPMD1 laser with locked peak $\mathrm{e}_{2}$. Average beat frequency $26.578 \mathrm{MHz}$ gives the deviation $=17.4 \mathrm{kHz} ; \mathrm{StDev}=4.3 \mathrm{kHz}$ 
Preliminarily, some short-term measurements (1000 samples at sampling time $\tau=1 \mathrm{~s}$, i.e. $16.7 \mathrm{~min}$ ) were performed to find the position of the resonant tube with stable radiation frequency. Then, matrix measurements (for all non-diagonal pairs inside d, e, f, g quadruplet, Table 1) were performed for the determination of the LPMD1 frequency offset and the evaluation of the frequency stability, summarized in Table 3.a. They are comparable to the results of similar bilateral comparisons (Table 3.d, e). The data in Table 3.b were provided with the comb measurements of the MIRS1 laser, that were preliminary performed by the Wroclaw University of Technology, Poland, and after this LPMD1-MIRS1 inter-comparison, confirmed by BEV Federal Office of Metrology and Surveying, Austria (according to the procedure given in [5]). Neglecting possible influencing factors in the beat frequency procedure and simply taking the mutual uncertainty as a root of sum of squares of partial uncertainties for both lasers, the uncertainty for LPMD1 can be estimated (Table 3.c). The deviation of beat frequency is calculated as the difference between the measured and the theoretical value for a particular peak-peak pair. Several hour-long measurements, made immediately after the matrix (successive short) measurements on the last locked pair (Table 2, Fig. 3) showed that the variation in the deviations amongst different pairs (seen in Table 1) belongs to the frequency variation in the same time sequences $(1000 \mathrm{~s})$.

Table 3 Evaluation of frequency stability

\begin{tabular}{|l|c|c|c|}
\hline ASD at & (a) MIRS1 - LPMD1 & (b) MIRS1 & (c) LPMD1 \\
\hline $1 \mathrm{~s}$ & $2.65 \cdot 10^{-11}$ & $1.5 \cdot 10^{-11}$ & $2.2 \cdot 10^{-11}$ \\
\hline $10 \mathrm{~s}$ & $6.7 \cdot 10^{-12}$ & $5.0 \cdot 10^{-12}$ & $4.5 \cdot 10^{-12}$ \\
\hline $100 \mathrm{~s}$ & $1.9 \cdot 10^{-12}$ & $1.5 \cdot 10^{-12}$ & $1.2 \cdot 10^{-12}$ \\
\hline
\end{tabular}

\begin{tabular}{|l|l|}
\hline$(\mathrm{d})[10]$ & $(\mathrm{e})[11]$ \\
\hline$(1.5-3) \cdot 10^{-11}$ & $(1-4.4) \cdot 10^{-11}$ \\
\hline$(5-10) \cdot 10^{-12}$ & $(3-16) \cdot 10^{-12}$ \\
\hline$(2-4) \cdot 10^{-12}$ & $(1-4.5) \cdot 10^{-12}$ \\
\hline
\end{tabular}

Long-term measurements through the night in a $10 \mathrm{~s}$ sampling period provided data for the estimation of the power coefficient. Preparatory short-term measurements of the MIRS1 power at different peaks (Fig. 4) showed that the values are close for different peaks, in the range of expanded uncertainty $(103.5 \pm 2) \mu \mathrm{W}$.
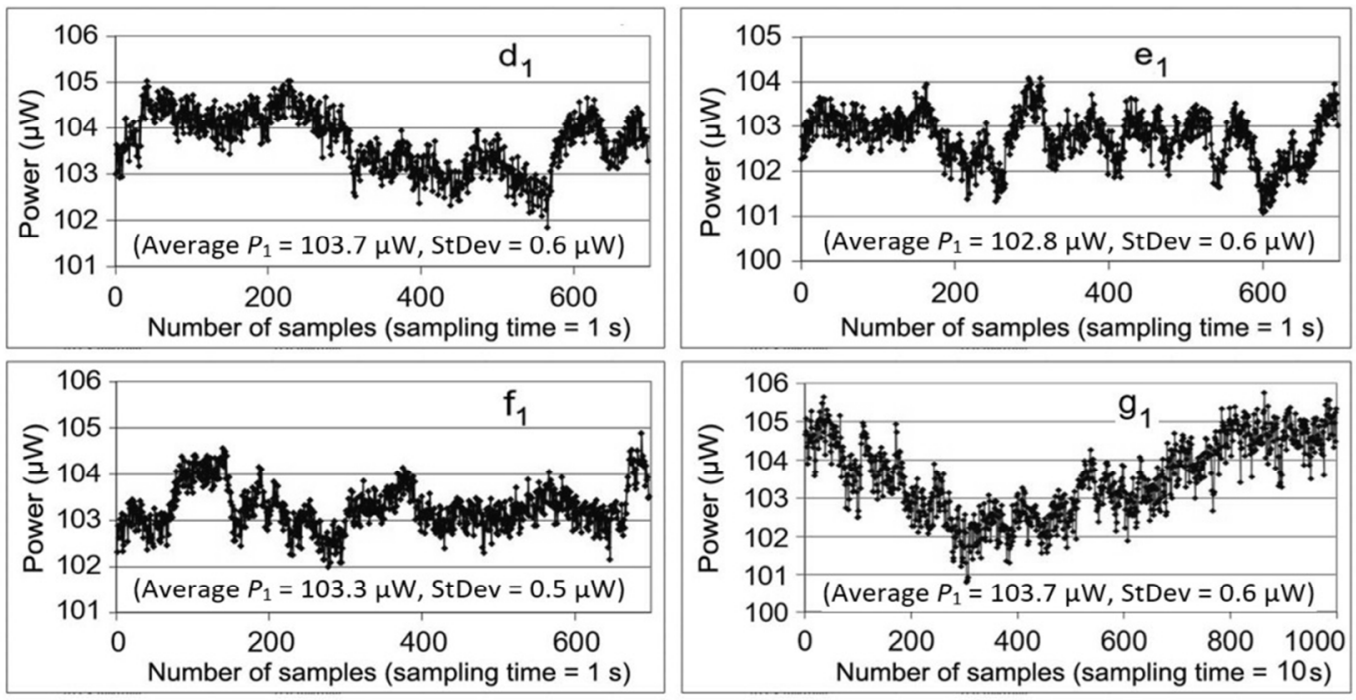

Fig. 4 Some preliminary measurements of MIRS1 power 

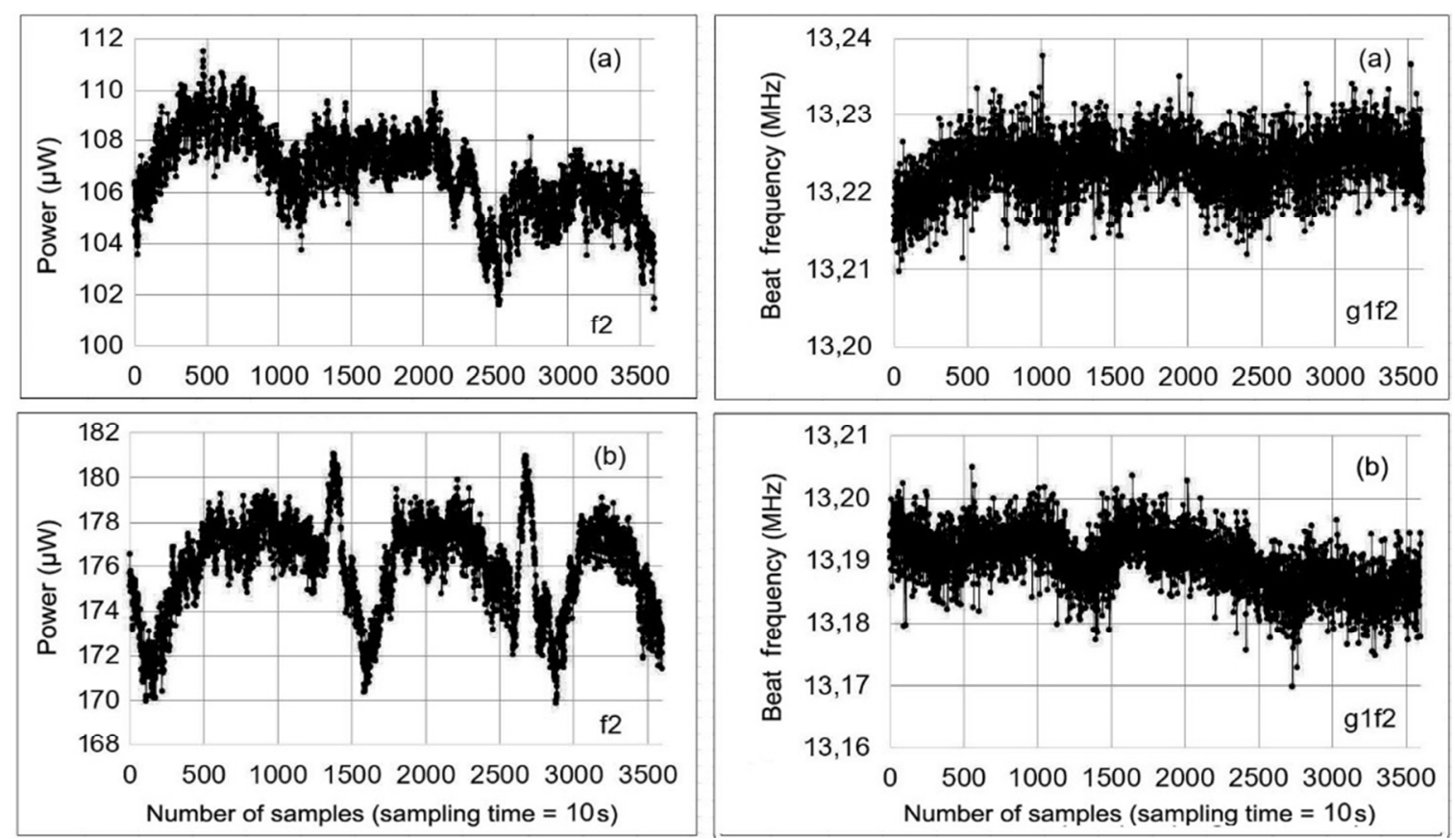

Fig. 5 Measurements of $P_{2}$ for determination of power sensitivity coefficient of LPMD1:

(a) Average $P_{2}=106.8 \mu \mathrm{W}, \mathrm{StDev}=1.6 \mu \mathrm{W}$; Beat freq. $=13.223 \mathrm{MHz}$, Deviation $=25 \mathrm{kHz}, \mathrm{StDev}=3.6 \mathrm{kHz}$;

(b) Average $P_{2}=176.0 \mu \mathrm{W}$, StDev $=2.1 \mu \mathrm{W}$; Beat freq. $=13.190 \mathrm{MHz}$, Deviation $=-8 \mathrm{kHz}$, StDev $=4.5 \mathrm{kHz}$.

As a reference peak $\mathrm{g}_{1}$ was taken, and a simultaneous observation of the LPMD1 power and beat frequency at locked $\mathrm{f}_{2}$ (Fig. 5) was performed. During the long-term measurements, the power was measured (with a Thorlabs S120C photodiode power sensor and a PM100USB power meter) by using a non-polarising 50:50 beam splitter in front of the LPMD1 laser, thus the results are multiplied by 2 before being plotted.

The standard deviation (StDev) values for the long-term beat frequency measurements in the $10 \mathrm{~s}$ sampling period (Figs. 2, 5) were below $5 \mathrm{kHz}$, while MEP recommends the threshold of $10 \mathrm{kHz}$ for a single laser (Table 4.a), which translates into the threshold of $14 \mathrm{kHz}$ for mutual uncertainty. The expected maximum of the total uncertainty for each laser was estimated from the most influencing parameters, RT, CFT, MW and $P$, their variations and sensitivity coefficients. After the key inter-comparison of MIRS1 [5], the resonant tube was readjusted at the Wroclaw University of Technology, Poland, and the power was increased, but other input data given in Table 4 remained the same. Despite a high variation of RT, its influence is negligible due to the relatively low sensitivity coefficient. In general, the total uncertainty is attributed to the variation of MW and CFT. Taking the estimation of $5 \mathrm{kHz}$ for MIRS1 (Table 4.b) and $4 \mathrm{kHz}$ for LPMD1 (Tab. 4.c) into account, the mutual uncertainty is expected to be $6.5 \mathrm{kHz}$ maximum. Thus, the measured uncertainty is close to the estimated uncertainty and it is small enough regarding the measurement accuracy required in the primary calibration procedures in which lasers are used as a reference, i.e. MIRS1 for the calibration of laser interferometers at the Laboratory for Production Measurements, and LPMD1 for the interferometric calibration of primary gauge blocks at the National Laboratory for Length. 
Table 4 Parameters influencing frequency uncertainty: MEP (2003) [1], (b) data for MIRS1 laser [5], and (c) for tested laser LPMD1 [5].

\begin{tabular}{|c|c|c|c|}
\hline (a) & MEP (2003) & Maximal coefficient & Maximal uncertainty \\
\hline RT & $(25 \pm 5){ }^{0} \mathrm{C}$ & $0.5 \mathrm{kHz} / \mathrm{K}$ & $2.5 \mathrm{kHz}$ \\
\hline CFT & $(15 \pm 0.2)^{0} \mathrm{C}$ & $-15 \mathrm{kHz} / \mathrm{K}$ & $3 \mathrm{kHz}$ \\
\hline MW & $(6 \pm 0.3) \mathrm{MHz}$ & $-10 \mathrm{kHz} / \mathrm{MHz}$ & $3 \mathrm{kHz}$ \\
\hline$P$ & $(100 \pm 50) \mu \mathrm{W}$ & & \\
\hline $\mathrm{f}$ & $473612353604 \mathrm{kHz}$ & & $10 \mathrm{kHz}$ \\
\hline (b) & MIRS1 & Maximal coefficient & Maximal uncertainty \\
\hline RT & $30(2){ }^{0} \mathrm{C}$ & $0.2 \mathrm{kHz} / \mathrm{K}$ & $0.4 \mathrm{kHz}$ \\
\hline CFT & $15(0.1)^{0} \mathrm{C}$ & $-18 \mathrm{kHz} / \mathrm{K}$ & $1.8 \mathrm{kHz}$ \\
\hline MW & $6(0.3) \mathrm{MHz}$ & $-16 \mathrm{kHz} / \mathrm{MHz}$ & $4.8 \mathrm{kHz}$ \\
\hline $\mathrm{P}$ & $103.5(2) \mu \mathrm{W}^{*}$ & $-0.15 \mathrm{kHz} / \mu \mathrm{W}$ & $0.3 \mathrm{kHz}$ \\
\hline $\mathrm{f}_{1}$ & $473612353604 \mathrm{kHz}$ & & $5.2 \mathrm{kHz}$ \\
\hline (c) & LPMD1 & Maximal coefficient & Maximal uncertainty \\
\hline $\mathrm{RT}$ & $24(1){ }^{0} \mathrm{C}$ & $0.2 \mathrm{kHz} / \mathrm{K}$ & $0.2 \mathrm{kHz}$ \\
\hline CFT & $15.0(0.3){ }^{0} \mathrm{C}$ & $-12.5 \mathrm{kHz} / \mathrm{K}$ & $3.75 \mathrm{kHz}$ \\
\hline MW & $6(0.2) \mathrm{MHz}$ & $-7.6 \mathrm{kHz} / \mathrm{MHz}$ & $1.5 \mathrm{kHz}$ \\
\hline $\mathrm{P}$ & $125(2) \mu \mathrm{W}$ & $-0.5 \mathrm{kHz} / \mu \mathrm{W}$ & $1 \mathrm{kHz}$ \\
\hline $\mathrm{f}_{2}$ & $473612353621 \mathrm{kHz}$ & & $4.2 \mathrm{kHz}$ \\
\hline
\end{tabular}

Calculating the f-frequency offset for LPMD1 (Table 4.c), the alternating sign of deviations for complementary peak-peak pairs (Table 1) determines the following relationships:

measured $\mathrm{g}_{1}=$ theoretical $\mathrm{g}-$ MIRS1 offset, and measured $\mathrm{f}_{2}=$ theoretical $\mathrm{f}+$ LPMD1 offset, so measured $\left(f_{2}-g_{1}\right)$ difference $=$ theoretical $(f-g)$ difference $+($ MIRS1 offset + LPMD1 offset $)$, measured $\left(\mathrm{f}_{1}-\mathrm{g}_{2}\right)$ difference $=$ theoretical $(\mathrm{f}-\mathrm{g})$ difference $-($ MIRS1 offset + LPMD1 offset),

and similarly for other pairs, taking into account that the values are decreasing along the quadruplet d, e, f, g. An exception can be seen in Fig. 5.b, where the power increased so high that the deviation already crossed zero:

measured $(\mathrm{f} 2$-g1) difference $=$ theoretical $(\mathrm{f}-\mathrm{g})$ difference $+($ MIRS1 offset - LPMD1 offset).

\section{Conclusion}

The use of iodine stabilized He-Ne lasers for practical realization of the metre is essential for establishing traceability in length metrology. While numerous publications deal with their use and performance, very little information is available on their maintenance most importantly, on the consequences of changing the resonant tube. Tube positioning and alignment within the optical cavity is not a simple process, but even when it is successfully done, the question of influence of intra-cavity power on laser frequency and stability still remains. It is shown that this parameter can be successfully isolated in a heterodyne comparison with another iodine stabilized primary laser. Furthermore, it is demonstrated that, at least for the resonant tube used to replace the original tube design in LPMD1, the resulting laser set-up is sufficiently stable to satisfy the requirements of MEP.

Acknowledgement: The authors acknowledge the financial support from the Slovenian Research Agency (research core funding No. P2-0190) as well as from the Metrology Institute of the Republic of Slovenia (funding of national standard of length; contract No. C3212-10000072). Furthermore, comb measurements of the MIRS1 laser performed by BEV Federal Office of Metrology and Surveying, Austria, and by the Wroclaw University of Technology, Poland, are highly appreciated. 


\section{REFERENCES}

[1] Quinn, T.J. (2003). Practical realization of the definition of the metre, including recommended radiations of other optical frequency standards (2001). Metrologia, Vol. 40, No. 2, 103-133, ISSN 0026-1394, https://doi.org/10.1088/0026-1394/40/2/316

[2] Lipus, L.C.; Matus, M. \& Acko, B. (2013). Optimization of calibrating HeNe laser interferometers by sample-period simulation. International Journal of Simulation Modelling, Vol. 12, No. 3, 154-163, ISSN 1726-4529, https://doi.org/10.2507/IJSIMM12(3)2.231

[3] Klobucar, R. \& Acko, B. (2017). Automatic high resolution measurement set-up for calibrating precise line scales. Advances in production engineering \& management, Vol. 12, No. 1, 88-96, ISSN 1854-6250, https://doi.org/10.14743/apem2017.1.242.

[4] Mudronja, V.; Katic, M. \& Simunovic, V. (2014). Realization of the highest level of traceability in Croatian National Laboratory for Length. Transactions of Famena, Vol. 38, No. 1, 37-44, ISSN 13331124

[5] Matus, M.; Nyholm, K.; Madej, A.; Bernard, J.E.; Walczuk, J.; Lipus, L.C. et al. (2010). The CCL-K11 ongoing key comparison 2007 - 2009, Metrologia, Vol. 47, Supp. 1, ISSN 0026-1394, https://doi.org/10.1088/0026-1394/47/1A/04009

[6] Acko, B.; Brezovnik, S. \& Sluban, B. (2013). Verification of software applications for evaluating interlaboratory comparison results, 24th DAAAM International Symposium, B. Katalinic (Ed.), Oct. 2013, Zadar, Croatia, Vol. 24, No. 1, ISSN 2304-1382, DAAAM International Vienna, Vienna, Procedia Engineering 69 (2014), 263-272, https://doi.org/10.1016/j.proeng.2014.02.231

[7] Acko, B.; Sluban, B.; Tasic, T. \& Brezovnik, S. (2014). Performance metrics for testing statistical calculations in interlaboratory comparisons. Advances in Production Engineering \& Management, Vol. 9, No. 1, 44-52, ISSN 1854-6250, https://doi.org/10.14743/apem2014.1.175

[8] Acko, B.; Brezovnik, S.; Lipus, L.C. \& Klobucar, R. (2015). Verification of statistical calculations in interlaboratory comparisons by simulating input datasets. International Journal of Simulation Modelling, Vol. 14, No. 2, 227-237, ISSN 1726-4529, https://doi.org/10.2507/IJSIMM14(2)4.288

[9] Lipus, L.C.; Budzyn, G.; Rzepka, J. \& Acko, B. (2016). Calibration Capability With Laser Capability Standard, Chapter 18 in DAAAM International Scientific Book 2016, 197-206, B. Katalinic (Ed.), Published by DAAAM International, ISBN 978-3-902734-09-9, ISSN 1726-9687, Vienna, Austria https://doi.org/10.2507/daaam.scibook.2016.18

[10] Navratil, V.; Matus, M.; Fira, R. \& Fodrekova, A. (2002). International comparison of He-Ne lasers stabilized with I-121(2) at lambda approximate to $633 \mathrm{~nm}$ between the SMU (Slovakia) and the BEV (Austria), Metrologia, Vol. 39, No. 2, 213-217, ISSN 0026-1394, https://doi.org/10.1088/0026-1394/39/2/9

[11] Matus, M.; Balling, P.; Smid, P.; Walczuk, J.; Banreti, E.; Tomanyiczka, K.; Popescu, G.H.; Chartier, A. \& Chartier, J.-M. (2002). International comparison of He-Ne lasers stabilized with I-121(2) at lambda approximate to $633 \mathrm{~nm}$ (September 1999) - Part IX: Comparison of BEV (Austria), CMI (Czech Republic), GUM (Poland), OMH (Hungary), NIPLPR (Romania) and BIPM lasers at lambda approximate to $633 \mathrm{~nm}$, Metrologia, Vol. 39, No. 1, 83-89, ISSN 0026-1394, https://doi.org/10.1088/0026-1394/39/1/10

Submitted: $\quad$ 15.7.2019

Accepted: $\quad 08.10 .2019$
Assist. prof. dr. Lucija Č. Lipuš University of Maribor, Faculty of Mechanical Engineering, Smetanova 17, 2000 Maribor, Slovenia

Assist. prof. dr. Marko Katić Marko.katic@fssb.hr University of Zagreb, Faculty of Mechanical Engineering and Naval Architecture, Ivana Lucica 5, Zagreb, Croatia 